\title{
O perfil do Tradutor Público e Intérprete Comercial: um estudo sobre competências tradutórias
}

\section{The Public Translator's profile: a study about translation competences}

\author{
Jonatã José Roberto Cardoso Nanetti \\ Leila Maria GumushianFelipini*
}

Resumo:A profissão de Tradutor Público e Intérprete Comercial é a única regulamentada na área da tradução. Uma vez que os documentos que constituem a sua regulamentação se limitam a descrever as atividades realizadas pelos profissionais e como essas devem ser cumpridas perante a Lei, o presente estudo teve $\mathrm{o}$ intuito de estabelecer um perfil recomendado aos Tradutores Públicos e Intérpretes Comerciais, por meio de levantamento bibliográfico, documental e exploratório. A teoria utilizada contempla Aubert (1987, 1996, 1998, 2005), Aubert e Tagnin (2004), Pagano (2013), Alves (2013) e Albir (2005). Foi possível identificar que a formação formal fornece ao tradutor a otimização das subcompetências tradutórias responsáveis pelo bom desenvolvimento profissional, embora a maioria dos tradutores em atuação hoje em dia não possua tal formação.

\footnotetext{
"Bacharel em Letras-Tradutor pela Universidade do Sagrado Coração. E-mail: jcnanetti@gmail.com.

"Possui graduação em Tradutor pela Universidade do Sagrado Coração - Bauru - SP (2001), mestrado em Linguística Aplicada e Estudos da Linguagem pela Pontifícia Universidade Católica de São Paulo (2012) e doutorado em Ciências pelo programa de Fonoaudiologia pela Faculdade de Odontologia de Bauru da Universidade de São Paulo - FOB/USP (2016). Professora na graduação nos cursos de Letras - Tradutor e Letras - Português e Inglês e coordenadora do PIBID MULTIDISCIPLINAR, na Universidade do Sagrado Coração. E-mail: leilafelipini@yahoo.com.br.
} 
Palavras-chave:Tradutor Público e Intérprete Comercial; Tradução Juramentada; Competência Tradutória.

Abstract:The Public Translator profession is the only one which is regulated in the field of translation. Since the documents that constitute the regulation of the profession are restricted todescribing the activities performed by the professionals and how these activities must be fulfilled before the Law, this study aimed to establish a recommended profile to Public Translators, by means of bibliographic, documental, and exploratory research. The theory used contemplates Aubert (1987, 1996, 1998, 2005), Aubert andTagnin (2004), Pagano (2013), Alves (2013) andAlbir (2005). It was possible to identify that the formal education provides the optimization of the translation subcompetences responsible for good professional performance, though most translators working nowadays do not have such education.

Keywords:Public Translator; Sworn Translation; Translation Competence.

\section{Introdução}

O ofício de Tradutor Público e Intérprete Comercial não é recente. Em 1808, com o aumento das frotas de navios em portos brasileiros, D. João VI viu a necessidade de criar um intérprete para suprir as necessidades linguísticas dos comerciantes brasileiros e dos responsáveis pelos navios (WYLER 2003). A partir desse momento, a necessidade por nomear intérpretes aumentou.

Em 1823, momento em que o ofício de tradutor passa a ser associado ao de intérprete, o título conferido ao Tradutor Público e Intérprete Comercial era “traductor jurado da Praça e intérprete da Nação”. No entanto, foi somente em 1850 (WYLER 2003), que o Código e o Regulamento comerciais passaram a determinar que os documentos redigidos em países estrangeiros seriam considerados traduzidos em língua nacional quando a tradução fosse realizada por intérprete público nomeado pelos Tribunais de Comércio.

Somente no ano seguinte, um Decreto Imperial estabelece regulamento para os Intérpretes de Commercio da Praça do Rio de Janeiro, tendo sua nomeação e a fixação dos seus emolumentos delegadas ao Tribunal do Comércio da capital do império. Em 1890, as Juntas Comerciais receberam regulamento garantindo todas as competências para nomear seus intérpretes. 
0 ofício de intérprete de comércio foi mantido igual por aproximadamente cem anos, sofrendo alterações somente em 1943, com o Decreto 13.609, o qual estabeleceu que a nomeação de Tradutor Público e Intérprete Comercial seria feita mediante concurso público classificatório.

A profissão de Tradutor Público e Intérprete Comercial é a única, na área de tradução, que é regulamentada. Seu regulamento encontra-se no Decreto n 13.609, de 21 de outubro de 1943, do presidente Getúlio Vargas, e por dispositivos legais posteriores. De acordo com a Legislação Federal, "o Ofício de Tradutor Público e Intérprete Comercial será exercido, no país, mediante concurso e a sua nomeação concedida pelas Juntas Comerciais ou órgãos encarregados do registro do comércio" (BRASIL 1943: 1).

Sendo assim, tanto os concursos públicos quanto os aspectos práticos do ofício são definidos pela Junta Comercial de cada estado, que estabelece quais serão as atividades realizadas pelos tradutores, a forma e o valor que cobrarão dos clientes e como devem agir legalmente de acordo com as normas estabelecidas tanto pelo Decreto Federal quanto pelas Deliberações estipuladas pelas Juntas Comerciais.

Mesmo a atuação de Tradutor Público e Intérprete Comercial sendo regulamentada, os documentos que constituem essa regulamentação se limitam a descrever suas atividades e como essas devem ser cumpridas perante a Lei. Em nenhum momento, os documentos mencionam o perfil necessário para se executar o ofício de Tradutor Público e Intérprete Comercial. Entendemos por perfil, o conjunto de estratégias, habilidades e conhecimentos que compõe a competência tradutória necessária ao profissional da área, características que são avaliadas somente no momento em que a prova é realizada.

\footnotetext{
Art. $5^{\circ}$ - As provas escrita e oral compreenderão:

I - prova escrita, constando de versão, para o idioma estrangeiro, de um trecho de trinta ou mais linhas, sorteado no momento, de prosa em vernáculo, de bom autor; e de tradução para o vernáculo de um trecho igual, preferencialmente de cartas rogatórias, procurações, cartas partidas, passaportes, escrituras notarias, testamentos, certificados de incorporação de sociedades anônimas e seus estatutos;

II - prova oral, consistindo em leitura, tradução e versão, bem como em palestra, com arguição no idioma estrangeiro e no vernáculo,
} 
que permita verificar se 0 candidato possui o necessário conhecimento e compreensão das sutilezas e dificuldades de cada uma das línguas. (BRASIL2013: 5)

Desta forma, considerando importante verificar de forma mais aprofundada qual seria esse perfil, verificamos o que a literatura da área da tradução propõe como competências necessárias para a atuação do tradutor, além de fazer o levantamento de tais competências na perspectiva do Tradutor Público e Intérprete Comercial em atuação.

Para tanto, utilizamos as contribuições acerca da tradução juramentada de Aubert (1987, 1996, 1998, 2005) e Aubert e Tagnin (2004) e acerca da competência tradutória e das estratégias de tradução de Adriana Pagano, e Fábio Alves (In: Pagano; Magalhães; Alves 2013) e de Albir (In: Pagano; Magalhães; Alves2005)

\section{Tradução juramentada}

A tradução juramentada possui especificidades que se divergem das demais áreas tradutórias, pois valida documentos redigidos em idiomas estrangeiros em todo o território nacional. Conforme estabelecido pelo Artigo 18 do Decreto 13.609/43, nenhum livro, documento ou escrito, de qualquer natureza, produzirá efeito legal se não estiver acompanhado de sua respectiva tradução. Assim estabelecido, a tradução não substitui o original, como nas demais modalidades de tradução, mas o complementa (AUBERT 2005).

Sendo assim, o Tradutor Público e Intérprete Comercial se difere de qualquer outro profissional da tradução, pois suas traduções têm Fé Pública, o que "implica em confiança, credibilidade e crédito, quesitos fundamentais para a expressão da verdade" (GoEDERT2015: 28). Uma vez que se obtém o ofício para atuar na área, o tradutor obtém jurisdição em todo o estado no qual the foi garantido o ofício e sua tradução é reconhecida em todo território nacional, tornando-se um documento. De acordo com Aubert (1998), tradução juramentada é: 
A tradução de textos - de qualquer espécie - que resulte em um texto traduzido legalmente reconhecido como uma reprodução fiel do original (com fé pública). Esta característica de fidelidade, por sua vez, significa que, por meio de tal tradução, o texto original, expresso em um idioma estrangeiro, torna-se capaz de produzir efeitos legais no país da língua de chegada e, ainda, que tal tradução é correta, precisa, exaustiva e semanticamente invariante em relação ao original (obviamente, dentro dos limites dos meios de expressão disponíveis nas respectivas línguas/culturas que se confrontam no ato tradutório específico). (AUBERT 1998: 14)

Apesar de Aubert (1987, 1996, 1998, 2004, 2005), entre outros teóricos, recomendar o uso da tradução literal para esses tipos de texto, o mesmo enfatiza a existência de limites impostos pelos meios de expressão disponíveis nas respectivas línguas/culturas.

\section{Tradução literal}

A tradução literal pode ser entendida como um procedimento técnico caracterizado pela fidelidade do tradutor ao léxico e à semântica do texto original. Para Aubert (1987: 15), existem várias possibilidades de explicitação para esse conceito, sendo o que mais se aplica à tradução juramentada “[...] aquela em que se mantém uma fidelidade semântica estrita, adequando, porém, a morfossintaxe às normas gramaticais da LC. "

Considerando as peculiaridades da tradução juramentada, além de sua “intenção comunicativa” na cultura de chegada, Aubert afirma que

[...] a expectativa de invariância semântica relativamente ao original sugere uma certa ênfase na valorização do original, uma tendência a adotar soluções literais ou quaseliterais, com vínculos estreitos não apenas no sentido mas, igualmente, à forma do original, mais do que buscar formas equivalentes de uso corrente na língua de chegada. (AUBERT 1996: 107)

Com relação aos limites impostos pelos meios de expressão disponíveis nas respectivas línguas/culturas, Aubert argumenta (2005) que os textos submetidos a traduções juramentadas possuem fortes marcas culturais linguísticas e extralinguísticas, o que exigiria do tradutor um trabalho de 
reescrita e readequação cultural. Porém, essas traduções devem "ater-se, de forma bastante estrita, à estrutura e fraseologia do original” (AUBERT 1987), pois a "tradução juramentada deve 'espelhar' o original, não melhorá-lo. " (AUBERT 2005)

Enquanto uma tradução simples substitui o texto original, as traduções juramentadas são apresentadas acompanhadas deles, pois "sua intenção é a de auxiliar o receptor no entendimento do texto original e na moldura de seu contexto cultural de origem" (AUBERT;TAGNIN 2004: 165), o que resultaria em soluções literais para os textos dessa área tradutória.

Considerando o exposto acima, podemos observar que Aubert recomenda o uso da literalidade e a valorização da estrutura da língua de partida, mas também indica em vários momentos a necessidade de se considerar as questões culturais entre os textos de partida e de chegada.

\section{Estratégias de tradução}

Para realizar uma tradução adequada é preciso que o tradutor possua estratégias de diversas naturezas, que podem ser adquiridas pelo estudo formal da tradução e desenvolvidas pela experiência. Um dos maiores equívocos acerca da tradução está diretamente ligado à crença de que sua prática requer apenas conhecimento linguístico. Segundo Pagano (2013) “é preciso relembrar que a tradução requer uma formação e uma qualificação que fornecem ao tradutor as habilidades e conhecimentos suficientes para uma boa performance."

A competência linguística é essencial no processo tradutório, mas não é suficiente. Alves (2013: 113) entende esse processo como "uma tarefa de coordenadas múltiplas, em constante mutação, que reafirma a necessidade de se trabalhar a tradução de acordo com as características de aprendizagem individuais e os mecanismos de operação cognitiva dos tradutores em formação." Sendo assim, é necessário combinarmos e integrarmos diferentes estratégias para tomar uma decisão de tradução, pois seu processo ocorre por meio de apoios múltiplos do sistema cognitivo. 
Destarte, para uma boa performance, o tradutor precisa realizar algumas ações, muitas das quais, segundo Pagano (2013), são realizadas de forma automática, subconsciente, enquanto que outras partem de decisões conscientes e cuidadosamente tomadas. Para a autora, tais ações constituem formas de resolução de problemas, as quais chamamos de estratégias. Essas ações são caracterizadas (PAGANo 2013) pelas dúvidas e perguntas que devemos solucionar durante o processo de leitura, interpretação e recriação do texto, tendo como base nosso conhecimento prévio, linguístico e cultural, além de pesquisas que devem ser feitas fora do texto.

Segundo Alves (2013), no modelo proposto pelo alemão Frank Krönigs "as atividades de tradução são agrupadas em dois grandes blocos: o Bloco Automático (Adhoc-Block) e o Bloco Reflexivo (Rest-Block)."

No Bloco Automático acontecem as correspondências automáticas para as Unidades de Tradução que já estão intrínsecas em nosso conhecimento, ou seja, o tradutor dispõe de equivalências já preestabelecidas. No entanto, quando essas Unidades de Tradução necessitam de reflexão por parte do tradutor, passamos para o Bloco Reflexivo, isto é, o tradutor precisa de habilidades e estratégias mais complexas para solucionar os problemas no processo tradutório. Alves (2013) reformula a proposta de Krönigs, redividindo o processo tradutório em sete etapas processuais, com o intuito de "sensibilizar e conscientizar o tradutor em formação".

A Automatização e o Bloqueio Processual acontecem no Bloco Automático, e tratam-se, respectivamente, de solucionar de modo automático problemas de Unidades de Tradução presentes no texto, sem precisar de apoio externo, e de não conseguir operar uma Unidade de Tradução "por falta de competência linguística ou de competência tradutória." (ALVES 2013: 116)

0 Apoio Externo é utilizado quando o tradutor desconhece totalmente a Unidade de Tradução e precisa utilizar "instrumentos externos que o ajudem na tarefa de traduzir" (ALVEs 2013: 116). Nesse caso, o tradutor pode fazer o uso de dicionários, sites de internet, glossários ou qualquer outra fonte de consulta confiável.

Ao tratar de Apoio Interno, Alves (2013: 116) cita dois tipos, sendo eles "apoio interno, com a recuperação de memória para a tradução de uma 
Unidade de Tradução já conhecida; e outro tipo de apoio interno, sem recuperação de memória e sem conhecimento anterior da Unidade de Tradução em questão." Sendo assim, o apoio interno pode envolver operações mentais, quando o tradutor tem como base conhecimentos já intrínsecos, ou mecanismos inferenciais que têm como base a bagagem de conhecimento do tradutor.

Em muitos casos, o tradutor precisará unir o apoio externo e o apoio interno para solucionar determinados problemas de tradução. Alves (2013: 117) denomina essa etapa como Combinações de Apoio Externo e Interno, e afirma que "por meio da própria experiência, o tradutor aprende a reconhecer quando uma destas fontes de apoio se esgotou e passa, então, a utilizar, alternativamente, os recursos de um outro tipo de processamento cognitivo."

$\mathrm{Na}$ etapa de Priorização e Omissão de Informações, o tradutor faz as escolhas sobre a priorização de informações relevantes e omissão de informações menos relevantes. Para Alves (2013: 117) "nesse momento, o tradutor precisa saber trabalhar com a priorização e a omissão das informações contidas no texto de partida para poder decidir como transpô-las para o texto de chegada."

Por fim, o tradutor tem a possibilidade de revisar todo o processo tradutório na etapa de Aperfeiçoamento do Texto de Chegada, podendo aperfeiçoar as Unidades de Tradução e alterar o que ainda considera insatisfatório.

\section{Competência tradutória}

Considerando que a tradução é um conhecimento adquirido e aprimorado por meio da formação e da experiência e que, portanto, requer uma formação e uma qualificação que propicie ao tradutor habilidades e conhecimentos eficientes para uma boa performance (PAGANO 2013), existe a necessidade de se caracterizar competência tradutória. Pagano (2013: 13) define competência tradutória como "todos aqueles conhecimentos, 
habilidades e estratégias que o tradutor bem-sucedido possui e que conduzem a um exercício adequado da tarefa tradutória."

Segundo Albir (2005), somente na década de 1980 o termo competência tradutória passou a ser utilizado e existem várias propostas de modelos que se preocupam em descrever os seus componentes. Para a autora (2013: 23) "a disparidade de critérios sobre o funcionamento da competência tradutória não faz senão destacar a complexidade de sua descrição e a variedade dos subcomponentes que a integram."

O grupo PACTE (Processo de Aquisição da Competência Tradutória e sua Avaliação), preocupado em realizar investigações empírico-experimentais acerca da competência tradutória e sua aquisição, define competência tradutória como um conhecimento especializado, composto por conhecimentos:

[...] um conhecimento especializado que consiste em um sistema subjacente de conhecimentos, declarativos e, em maior proporção, operacionais, necessários para saber traduzir, que está composto de cinco subcompetências (bilíngue, extralinguística, conhecimentos sobre a tradução, instrumental e estratégica) e de componentes psicofisiológicos. (ALBIR 2005: 28)

A subcompetência bilíngue consiste emconhecimentos pragmáticos, sociolinguísticos, textuais e léxico-gramaticais necessários para a comunicação entre duas línguas. Segundo Albir (2005), esse é um conhecimento essencialmente operacional. A subcompetência extralinguística é composta por conhecimentos culturais e enciclopédicos sobre o mundo em geral e de âmbitos particulares. Albir (2005) considera esse um conhecimento declarativo. A subcompetência de conhecimentos sobre a tradução, conhecimento essencialmente declarativo (ALBIR 2005), consiste em conhecimentos teóricos que regem a tradução e sobre aspectos profissionais. A subcompetência instrumental, conhecimento essencialmente operacional (ALBIR 2005), baseia-se em conhecimentos relacionados ao uso das fontes de documentação e das tecnologias de informática e comunicação aplicadas à tradução. A subcompetência estratégica é composta por conhecimentos que garantem a eficácia do processo tradutório. Segundo Albir (2005: 29), essa subcompetência controla o processo tradutório e serve para 
[...] planejar o processo e elaborar o projeto tradutório (escolha do método mais adequado); avaliar o processo e os resultados parciais obtidos em função do objetivo final perseguido; ativar as diferentes subcompetências e compensar deficiências entre elas; identificar problemas de tradução e aplicar os procedimentos para sua resolução. (ALBIR 2005: 29)

Os componentes fisiológicos são caracterizados, segundo Albir (2005: 29) como

[...] componentes cognitivos, tais como memória, percepção, atenção e emoção; aspectos de atitude, como curiosidade intelectual, perseverança, rigor, espírito crítico. Conhecimento e confiança em suas próprias capacidades, conhecimento do limite das próprias possibilidades, motivação etc.; habilidades, tais como criatividade, raciocínio lógico, análise e síntese etc. (ALBIR 2005: 29)

É importante considerar que as subcompetências interagem com os componentes fisiológicos e estão inter-relacionadas, funcionando de maneira integrada para formar a competência tradutória e respeitando uma hierarquia na qual a subcompetência estratégica se encontra no centro do sistema, uma vez que controla todo o processo. Segundo Albir $(2005: 29,30)$ "a interação entre as subcompetências varia segundo: a direção (direta ou inversa), a combinação linguística, a especialidade (jurídica, literária etc.), o grau de experiência do tradutor, o contexto de tradução (tipo de tarefa, tempo etc.)."

\section{Metodologia}

Este é um estudo de cunho qualitativo, constituído de pesquisa bibliográfica, documental e exploratória. Trata-se de uma análise que visou estabelecer as competências necessárias ao Tradutor Público e Intérprete Comercial, característica que compõe o perfil do profissional, além de verificar, na perspectiva dos Tradutores Públicos e Intérpretes Comerciais, qual seria esse perfil. 
Primeiramente, desenvolvemos uma pesquisa documental envolvendo um Decreto Federal, uma Deliberação e uma Instrução Normativa que descrevem o ofício e determinam as leis referentes ao ofício de Tradutor Público e Intérprete Comercial.

Posteriormente, desenvolvemos um questionário constituído de perguntas abertas e fechadas, o qual foi elaborado pela plataforma Google Docs e enviado, após aprovação do Comitê de Ética da Universidade do Sagrado Coração, a 150 Tradutores Públicos e Intérpretes Comerciais em atuação no estado de São Paulo. Dos 150 tradutores convidados, 19 responderam ao questionário. Para o desenvolvimento da pesquisa, somente questões que fazem referência às perguntas de pesquisa foram consideradas.

Por fim, desenvolvemos uma revisão de literatura, analisando as principais características que devem ser levadas em consideração no processo de tradução de textos juramentados.

As competências que constituem o perfil recomendado ao Tradutor Público e Intérprete Comercial que se pretendeu alcançar foram discutidas com base nas teorias da tradução, além de análise de documentos e de linguagem dos dados provenientes dos questionários.

\section{Resultados e discussão}

Para analisarmos as competências necessárias para atuar como Tradutor Público e Intérprete Comercial, consideramos as respostas enviadas por 19 tradutores, com idade entre 30 e 80 anos e que atuam com diversos pares de idiomas, e que deram o aceite no formulário on-line antes de responderem às questões propostas.

Os 19 tradutores possuem nacionalidade brasileira, sendo que 3 informaram ser brasileiros naturalizados e 6 possuírem nacionalidade dupla. 0 período de posse no ofício ocorreu entre 1980 e 2015. Dos 19, 18 exercem a função de Tradutor Público e Intérprete Comercial por conta própria, em casa ou escritório, e apenas 1 informou estar aposentado. 
Todos os tradutores possuem nível de ensino superior, embora nenhum possuagraduação em Tradução. Segundo os dados coletados, 6 tradutores são formados em Letras e 3 em direito; 4 tradutores informaram apenas a instituição de ensino em que se formaram; e 6 tradutores informaram possuir graduação em outras áreas do conhecimento (Gráfico 01 ).

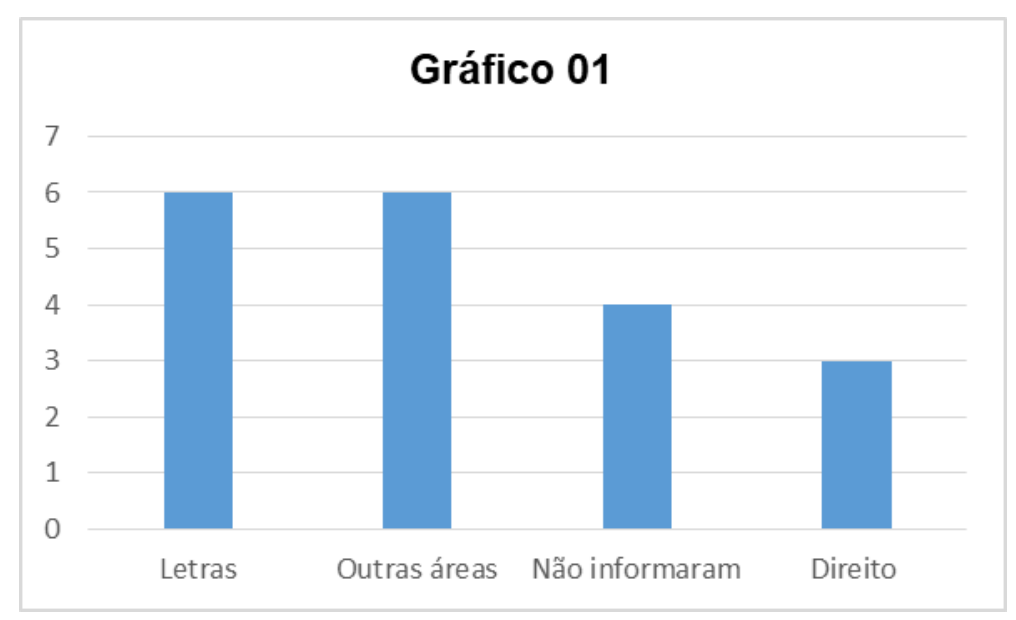

Fonte: elaborada pelo autor

Dos 19 tradutores, 12 disseram possuir uma especialização, sendo $3 \mathrm{em}$ tradução; 3 em línguas; 1 em interpretação; 1 em áreas ligadas ao direito e 4 informaram apenas ter especialização (Gráfico 02).

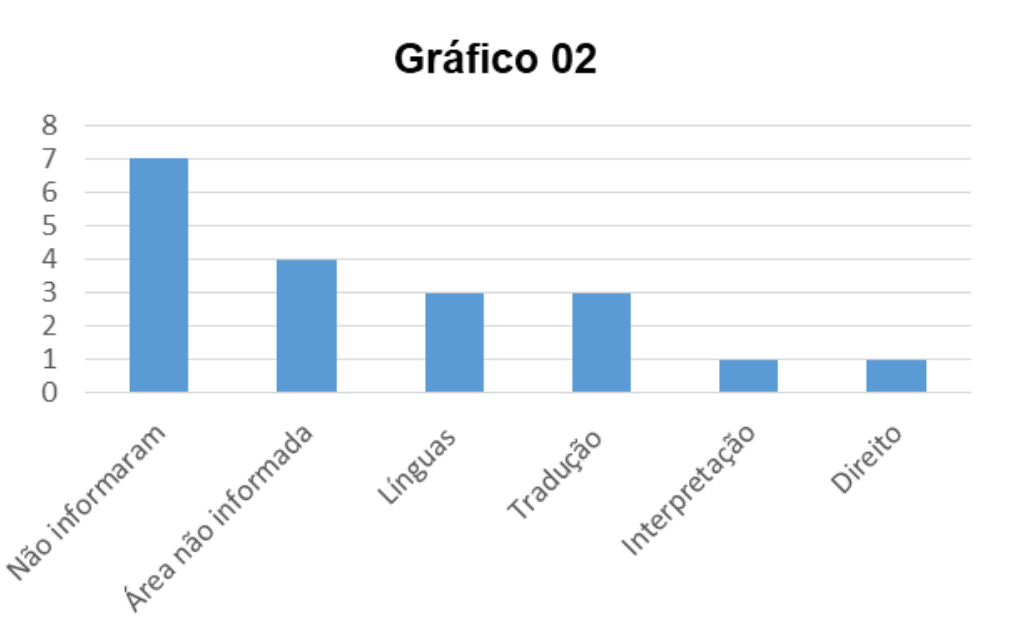

Fonte: elaborada pelo autor

Ao serem questionados sobre a titulação de mestrado ou doutorado, 7 tradutores disseram possuir a titulação de mestre, sendo apenas 1 na área de Tradução; 1 tradutor informou possuir a titulação de doutor na área de 
Línguas e 1 tradutor informou estar cursando doutorado, mas não citou a área.

Quanto aos cursos livres, 16 tradutores informaram ter cursado língua estrangeira; 7informaram ter frequentado cursos livres de tradução e/ou interpretação; 2 em tradução jurídica e 1 em tradução juramentada (Gráfico 03).

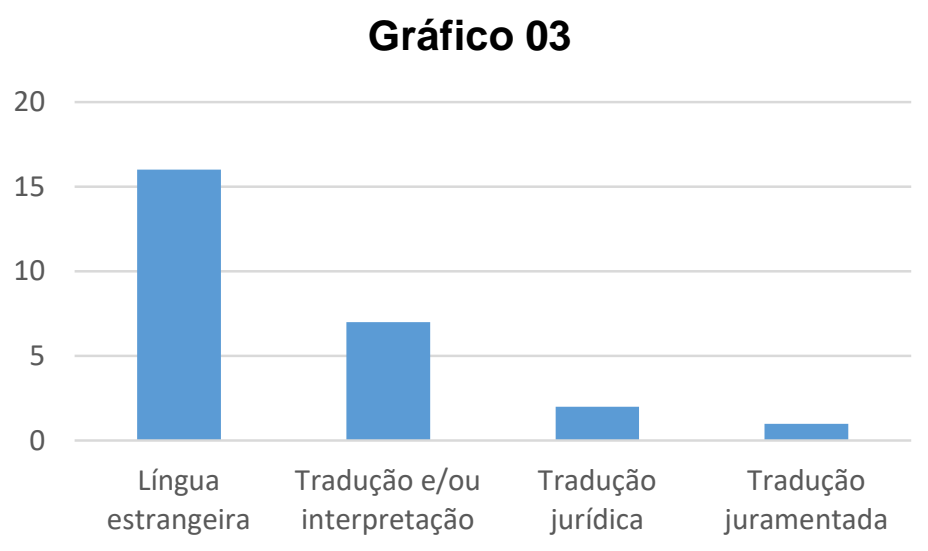

Fonte: elaborada pelo autor

$\mathrm{Na}$ questão sobre os cursos de tradução existentes nas instituições de ensino superior, 6 tradutores optaram por não responder; 6 disseram que os cursos são de boa qualidade; 3 consideram os cursos deficientes, pois são muito teóricos e apresentam problemas de conteúdo; 1 tradutor disse não ser necessáriatal formação; 1 queixou-se da falta de cursos para quem deseja trabalhar com outros idiomas que não o inglês; e 1 afirmou faltarem requisitos para os participantes. Além disso, 1 tradutor informou que os cursos de extensão da instituição $A$ são bons, mas que os cursos de especialização da instituição $B$ são deficientes.

Ao responderem se possuem algum vínculo com instituições de ensino, 7 informaram ser professores, 2 pesquisadores, 1 participante em pesquisa, 1 autor de livros didáticos, 1 revisor linguístico e 1 aluno. Entre esses, 2 tradutores informaram possuir mais de 1 vínculo (Gráfico 04 ). 


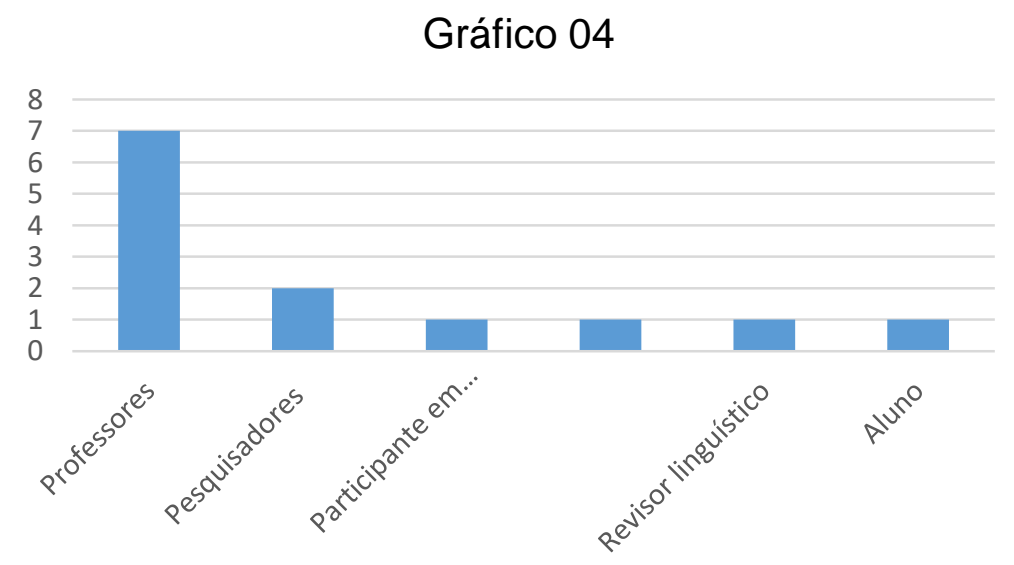

Fonte: elaborada pelo autor

As respostas fornecidas pelos Tradutores Públicos e Intérpretes Comerciais quanto à sua formação demonstram que o perfil da maioria desses profissionais em atuação não contempla o estudo formal da Tradução. É possível verificar que grande parte dos tradutores apresenta formação em Letras (6) e cursos livres relacionados a línguas (16). Sendo assim, observamos que existe uma maior preocupação com a competência linguística, que consideramos essencial para o processo tradutório, mas não suficiente para solucionar os desafios encontrados nesse processo. Segundo Albir (2005: 19) “embora qualquer falante bilíngue possua competência comunicativa nas línguas que domina, nem todo bilíngue possui competência tradutória." Para a autora (2005) a competência tradutória é um conhecimento especializado, enquanto o bilinguismo é uma subcompetência que compõe a competência tradutória. Albir (2005) caracteriza a competência bilíngue como um conhecimento operacional fundamental para a comunicação em duas línguas.

Foi possível identificar que mesmo nenhum tradutor possuindo graduação em tradução, esses se preocupam também com a competência tradutória, que é composta por habilidades e estratégias complexas adquiridas por meio do estudo (PAGANO 2013), uma vez que mesmo não contemplando o estudo formal, um número considerável de profissionais possui cursos livres e de especialização na área da Tradução (12). Pagano (2013) acredita que a formação formal e a qualificação do tradutor são essenciais para o exercício ético e adequado da profissão. Segundo a mesma autora (2013), traduzir vai além de conhecer uma língua e transpor palavras 
de uma língua para outra. A autora compreende tradução como recriação de um texto, o que só é possível se juntarmos o domínio de uma língua estrangeira com conhecimentos culturais e técnicos, e habilidades apropriadas (PAGano 2013).

Dos tradutores que frequentaram os cursos de especialização, a maioria informou que esses cursos são de boa qualidade. Apesar de não terem frequentado ou não conhecerem, dois tradutores consideram os cursos importantes para a formação do tradutor. Segundo Martins (apudNovaEs 2012: $5)$, os cursos de formação de tradutores começaram a surgir no Brasil no final da década de 60 e ainda são denominados "cursos de tradução". Considerando que com o passar do tempo esses cursos foram sofrendo modificações e se adaptando aos métodos de cada instituição e às mudanças no campo do conhecimento provocadas pelas ideias modernas e pós-estruturalistas no final da década de 70, que afetaram as grades curriculares dos cursos (NOVAES 2012), esses não apresentam uma padronização. É provável que a indeterminação de diretrizes curriculares gere uma falta de credibilidade com relação aos cursos, o que resulta em poucos tradutores profissionais formados na área. Sendo assim, os cursos de tradução requerem mudanças, para que haja uma padronização que enfatize o estudo prático e teórico, pois ambos contribuem de forma significativa para a aquisição da competência tradutória.

Ao responderem sobre as dificuldades encontradas no processo de tradução juramentada, foi possível perceber que a maior delas está relacionada à terminologia específica e a questões culturais. Outros 3 tradutores apontaram as demandas dos clientes, que muitas vezes não compreendem os prazos; 2 tradutores informaram não haver dificuldades; e 1 disse que textos mal redigidos também dificultam esse processo. (Tabela 01)

Partindo das respostas fornecidas pelos Tradutores Públicos e Intérpretes Comerciais quanto às dificuldades encontradas no processo tradutório de textos juramentados, foi possível identificar que a complexidade léxico-semântica existente nesse gênero causa grandes conflitos no momento de decidir qual a tradução mais adequada. Quanto mais especializada a linguagem, mais o tradutor deve se preocupar com a busca pelo equivalente mais adequado ao contexto. Pagano (2013) afirma que o 
tradutor experiente está atento à adequação de determinados termos no contexto no qual estão inseridos.

As dificuldades relatadas pelos tradutores em suas respostas são comuns ao processo tradutório de gêneros textuais submetidos à tradução juramentada. Para Aubert (1996), a intenção comunicativa do texto gera a expectativa de invariância semântica quanto ao original. 0 autor sugere que a estrutura do texto também devaser seguida de forma fiel, uma vez que a tradução deve auxiliar o entendimento do texto original e permanecer na moldura de seu contexto cultural, atuando como um espelho do original, o que resultaria em soluções literais durante o processo tradutório (AUBERT 2005).

Aubert (2005) identifica as fortes marcas culturais linguísticas e extralinguísticas presentes nos textos submetidos a traduções juramentadas, mas argumenta que tais características exigiriam um trabalho de reescrita e readequação cultural por parte do tradutor. 0 autor caracteriza a tradução juramentada, como exposto acima, por sua invariância semântica e discursiva em relação ao original e argumenta que o processo tradutório desses textos deveria voltar-se a soluções marcadas por um maior grau de literalismo formal (morfossintático) e semântico (conteúdo).

Observamos que a relação entre o tradutor e o cliente também pode ser conflitante, de acordo com as respostas concedidas pelos profissionais, pois muitas vezes o cliente não compreende o trabalho do tradutor $\mathrm{e}$, consequentemente, faz exigências que fogem da realidade cotidiana dos Tradutores Públicos e Intérpretes Comerciais. Robinson (apudPaGano 2013: 40) emprega a confiabilidade como uma atitude que deve ser desenvolvida para lidar com clientes e com os textos traduzidos. Desta forma, recomenda-seque o tradutor celebre um contrato de forma tácita com o cliente, de forma cordial e versátil, garantindo o cumprimento das metas, os prazos estabelecidos e assegurando a confidencialidade em seu trabalho (PAGano 2013).

Tabela 01

\section{\begin{tabular}{l|l} 
Tradutor 1 & Nenhuma em especial
\end{tabular}}




\begin{tabular}{|c|c|}
\hline Tradutor 2 & $\begin{array}{l}\text { Linguagem especializada - expectativas e demandas dos } \\
\text { clientes, as quais nem sempre se encontram em } \\
\text { conformidade com a realidade das condições de trabalho } \\
\text { do tradutor. }\end{array}$ \\
\hline Tradutor 3 & Os diferentes contextos em que um termo é utilizado. \\
\hline Tradutor 4 & Diversas, em geral resolvidas pela própria experiência. \\
\hline Tradutor 5 & $\begin{array}{l}\text { 1. O cliente quer o serviço para ontem. } \\
\text { 2. Os colegas trabalham com preços abaixo da tabela. }\end{array}$ \\
\hline Tradutor 6 & Não vejo muitas dificuldades. \\
\hline Tradutor 7 & $\begin{array}{l}\text { Falta de domínio de terminologia de áreas específicas do } \\
\text { conhecimento e nos diferentes países. }\end{array}$ \\
\hline Tradutor 8 & $\begin{array}{l}\text { Especificidade de termos e do campo específico do texto a } \\
\text { ser traduzido. }\end{array}$ \\
\hline Tradutor 9 & $\begin{array}{l}\text { Geralmente dificuldades terminológicas, sobretudo nas } \\
\text { áreas jurídica e contábil, pois há muita variação conforme } \\
\text { o país de origem ou de destino do texto. }\end{array}$ \\
\hline Tradutor 10 & Equivalências. \\
\hline Tradutor 11 & $\begin{array}{l}\text { Terminologia que exige muito cuidado e textos muito mal } \\
\text { redigidos. }\end{array}$ \\
\hline Tradutor 12 & $\begin{array}{l}\text { No caso do espanhol, a diversidade de termos jurídicos de } \\
\text { um país a outro. No caso do romeno, a existência de } \\
\text { documentos muito antigos, manuscritos, frequentemente } \\
\text { ilegíveis. }\end{array}$ \\
\hline Tradutor 13 & $\begin{array}{l}\text { No início, a minha falta de conhecimento sobre o } \\
\text { funcionamento de instituições e procedimentos, tanto } \\
\text { aqui no Brasil, quanto na Alemanha, embora já tivesse } \\
\text { vivido na Alemanha. Mas há conhecimentos que só a } \\
\text { experiência e a pesquisa trazem. Outra dificuldade é a } \\
\text { inexistência de termos correspondentes no outro idioma, } \\
\text { uma vez que a realidade e as instituições funcionam de } \\
\text { forma diferente. Há termos que são, de fato, } \\
\text { intraduzíveis. Nestes casos, lanço mão de observações } \\
\text { com esclarecimentos no final da tradução. Outra }\end{array}$ \\
\hline
\end{tabular}




\begin{tabular}{|c|l|}
\hline & $\begin{array}{l}\text { dificuldade é lidar com a burocracia e a má vontade da } \\
\text { Junta Comercial quanto ao registro dos livros, dos talões } \\
\text { de recibo, orientações sobre termos de abertura etc. }\end{array}$ \\
\hline Tradutor 14 & $\begin{array}{l}\text { Textos mal escritos são os que trazem maior dificuldade } \\
\text { (textos que não respeitam as normas da sintaxe) }\end{array}$ \\
\hline Tradutor 15 & $\begin{array}{l}\text { Não encontro nenhuma dificuldade operacional, apenas o } \\
\text { processo administrativo me parece um pouco maçante, } \\
\text { burocrático e desnecessário. }\end{array}$ \\
\hline Tradutor 16 & $\begin{array}{l}\text { Encontrar, nas versões, o melhor termo técnico na } \\
\text { variante do país onde a tradução será recebida. }\end{array}$ \\
\hline Tradutor 17 & $\begin{array}{l}\text { Encontrar o termo jurídico ou técnico equivalente na } \\
\text { outra língua. } \\
\text { Tradutor 18 }\end{array}$ \\
\hline Tradutor 19 & $\begin{array}{l}\text { Desconhecimento do público em geral quanto à } \\
\text { dificuldade do trabalho. }\end{array}$ \\
\hline
\end{tabular}

Fonte: elaborada pelo autor

Para solucionar as dificuldades encontradas no processo de tradução juramentada é necessário que o tradutor desenvolva habilidades e conhecimentos que possam melhorar seu desempenho. Ao responderem sobre isso, 10 tradutores disseram que é necessário possuir habilidades de pesquisa, em quaisquer que sejam os meios; 5 afirmaram que o conhecimento linguístico é suficiente como competência para um Tradutor Público e Intérprete Comercial; 4 disseram que é importante possuir conhecimentos das áreas para as quais se traduz; 3 ressaltaram questões culturais como importantes no processo tradutório; e 2 afirmam que saber ler é a maior das competências para poder entender e construir a lógica do texto e encontrar soluções aos problemas concretos da língua e do texto. (Tabela 02)

De acordo com as respostas fornecidas pelos Tradutores Públicos e Intérpretes Comerciais, foi possível identificar que as habilidades e conhecimentos mencionados como necessários para solucionar as dificuldades encontradas no processo tradutório e os recursos utilizados para auxiliar durante esse processo fazem referência às subcompetências que integram a competência tradutória estabelecida pelo grupo PACTE. 
Albir (2005) menciona a subcompetência instrumental, que consiste em conhecimentos operacionais concernentes ao uso das fontes de pesquisa e tecnologias de informática. Dessa forma, ao fazer uso de conhecimentos procedimentais, o tradutor desenvolve habilidades de pesquisa que o auxiliam no processo tradutório. Devido àterminologia específica da tradução juramentada, há alguns recursos que são utilizados com frequência pelos profissionais. Todos os tradutores informaram utilizar dicionário como principal fonte de pesquisa, seguido de pesquisas online e de glossários, 14 informaram utilizar textos paralelos e consultar profissionais especializados e apenas 8informaram utilizar memórias de tradução.

Alves (2013) salienta que é necessário que o tradutor desenvolva a capacidade de operar instrumentos externos que o ajudem durante sua tarefa, podendo ser consultas a dicionários, glossários, textos paralelos, consultas a outros profissionais e uso de memórias de tradução. Para Pagano (2013) dicionários bilíngues são limitados e o tradutor deve atentar-se à adequação de determinados termos no contexto em que serão inseridos. Para tanto, a autora recomenta o uso de dicionários monolíngues e enciclopédicos, pois oferecem informações mais completas para os tradutores.

Normalmente, os textos submetidos a tradução juramentada são documentos impressos, como carteira de identidade, carteira de motorista, diplomas, certificados, históricos escolares etc., o que sugere que o tradutor trabalhe com o texto original físico ou até mesmo digitalizado. Portanto, nem sempre é possível que o Tradutor Público e Intérprete Comercial faça o uso de memórias de tradução, o que exigiria a elaboração de glossários para consultas posteriores.

Pagano (2013) argumenta que traduzir é uma atividade que não exige apenas conhecimentos linguísticos. Para a autora, é necessário que combinemos esses conhecimentos com conhecimentos culturais e técnicos, a fim de obter uma tradução mais adequada. A competência bilíngue é necessária para a comunicação em outro idioma, no entanto o processo tradutório exige mais do tradutor. Alguns tradutores (5) ressaltaram que conhecer as línguas com as quais trabalham é essencial para o processo tradutório. Albir (2005) considera esse conhecimento como sendo apenas uma 
subcompetência da competência tradutória, caracterizada por conhecimentos operacionais essenciais para o procedimento tradutório, a qual denomina subcompetência bilíngue. Sendo assim, o bilinguismo apenas complementa o que os tradutores precisam saber para desenvolver traduções de qualidade.

0 conhecimento cultural tem importância significativa durante o processo tradutório de textos juramentados, mesmo sendo a tradução literal mais indicada para esse gênero, pois é necessário que o tradutor compreenda como funcionam as instituições, cargos e procedimentos em ambas as culturas com as quais trabalha. Albir (2005) caracteriza esse conhecimento como pertencente à subcompetência extralinguística.

Também é indicado que o tradutor possua conhecimentos teóricos acerca da tradução, o que o capacita a desenvolver habilidades para lidar com dificuldades durante o processo tradutório. Para Albir (2005), tal característica é essencial e funciona como uma subcompetência de conhecimentos sobre tradução. Nenhum tradutor citou essa característica como importante no momento de traduzir um texto submetido à tradução juramentada, o que reflete a ausência de formação formal na área.

Por fim, analisando as respostas concedidas pelos tradutores, é possível identificar que o conhecimento linguístico não é suficiente e que não supre todas as necessidades dos Tradutores Públicos e Intérpretes Comerciais.

Para exercer a função de tradutor de forma competente, é fundamental que o profissional também opere os componentes psicofisiológicos que compõem a competência tradutória proposta por Albir (2005). Alguns tradutores informaram que os aspectos dessa subcompetência são necessários para conseguir solucionar dificuldades durante o processo tradutório e obter um bom resultado, tais como adaptabilidade, agilidade, paciência etc. Assim, identificamos que suas respostas correspondem com o que Albir considera componente dessa subcompetência. Para a autora (2005), os componentes psicofisiológicos são componentes cognitivos e aspectos de atitude.

Para um bom resultado final é necessário que o tradutor trabalhe com a subcompetência estratégica proposta por Albir (2005), pois é um conhecimento operacional que controla o processo tradutório e ativa as 
diferentes subcompetências, as quais atuam de maneira integrada para formar a competência tradutória. Albir (2005: 29) salienta que essa subcompetência "ocupa um lugar essencial porque afeta a todas, uma vez que serve para reparar deficiências e controlar todo o processo."

Tabela 02

\begin{tabular}{|c|c|}
\hline Tradutor 1 & Conhecimento e prática. \\
\hline Tradutor 2 & Adaptabilidade, iniciativa, ética e razoabilidade. \\
\hline Tradutor 3 & $\begin{array}{l}\text { Capacidade de leitura e de pesquisa. Conhecer pessoas } \\
\text { que possam ajudar a resolver questões específicas. }\end{array}$ \\
\hline Tradutor 4 & $\begin{array}{l}\text { Perfeito domínio do vernáculo e da língua estrangeira } \\
\text { correspondente, formação e aperfeiçoamento nas áreas } \\
\text { específicas dos textos traduzidos/vertidos. }\end{array}$ \\
\hline Tradutor 5 & $\begin{array}{l}\text { 1. Trabalhar durante a noite. } \\
\text { 2. Aceitar a perda do cliente. }\end{array}$ \\
\hline Tradutor 6 & Não respondeu. \\
\hline Tradutor 7 & $\begin{array}{l}\text { Além da capacidade linguística, conhecimento geral, dos } \\
\text { processos econômicos, industriais, comerciais, } \\
\text { burocráticos, educacionais, sociais. Basicamente é ter } \\
\text { uma boa ideia de como as coisas funcionam nos vários } \\
\text { países e como e onde conseguir informações confiáveis. }\end{array}$ \\
\hline Tradutor 8 & $\begin{array}{l}\text { Conhecimento de áreas não especificamente ligadas a } \\
\text { línguas, conhecimentos gerais e culturais, consulta a livros } \\
\text { especializados, discussão com colegas em fóruns } \\
\text { especializado. }\end{array}$ \\
\hline Tradutor 9 & $\begin{array}{l}\text { Saber usar com agilidade as diversas ferramentas de } \\
\text { pesquisa. }\end{array}$ \\
\hline Tradutor 10 & Pesquisa e linguística de corpus. \\
\hline Tradutor 11 & $\begin{array}{l}\text { Pesquisas e estudos para a primeira dificuldade e cuidado } \\
\text { e experiência para entender e encontrar a melhor solução } \\
\text { no segundo caso. }\end{array}$ \\
\hline Tradutor 12 & No caso de traduções juramentadas, sites da internet. \\
\hline Tradutor 13 & Além de dominar o idioma, conhecer a realidade do país \\
\hline
\end{tabular}




\begin{tabular}{|c|c|}
\hline & $\begin{array}{l}\text { onde o idioma estrangeiro é falado é muito importante. } \\
\text { No meu caso, a especialização como intérprete me deu } \\
\text { muitas ferramentas para lidar com as dificuldades para a } \\
\text { tradução relacionadas às diferenças culturais. } \\
\text { Flexibilidade e mente aberta ajudam muito. }\end{array}$ \\
\hline Tradutor 14 & $\begin{array}{l}\text { Saber ler é a maior das competências para poder entender } \\
\text { e construir a lógica do texto e encontrar soluções aos } \\
\text { problemas concretos da língua e do texto. Saber pesquisar } \\
\text { para elucidar dúvidas também é fundamental. Ser } \\
\text { autodidata, paciente, rigoroso e disciplinado. Ter uma } \\
\text { ideia do que é ser um bom tradutor (algumas premissas } \\
\text { pessoais). }\end{array}$ \\
\hline Tradutor 15 & $\begin{array}{l}\text { Acredito que quem tenha bom conhecimento do idioma } \\
\text { que traduz/ao qual verte e tenha preparo em informática } \\
\text { e habilidade com a internet, se sairá bem como tradutor } \\
\text { público. }\end{array}$ \\
\hline Tradutor 16 & $\begin{array}{l}\text { Habilidade para buscas na internet, contato com falantes } \\
\text { da língua com conhecimento na área para solução de } \\
\text { dúvidas específicas. }\end{array}$ \\
\hline Tradutor 17 & $\begin{array}{l}\text { Conhecer bem as línguas pares e pesquisar muito na } \\
\text { internet e dicionários. }\end{array}$ \\
\hline Tradutor 18 & $\begin{array}{l}\text { O fundamental é não cair na armadilha da solução fácil, } \\
\text { ou seja, achar que o termo semelhante é o correto. }\end{array}$ \\
\hline Tradutor 19 & Explicar ao público, paciência. \\
\hline
\end{tabular}

Fonte: elaborada pelo autor

\section{Conclusão}

De acordo com a literatura utilizada, pudemos identificar que o ofício de tradutor demanda o desenvolvimento dehabilidades que o auxiliem durante o processo tradutório. Por meio do estudo formal da tradução e do acúmulo deexperiência, o tradutor capacita-se e aprimora as subcompetências que compõem a competência tradutória, as quais devem ser utilizadas no processo 
tradutório, sendo elas a bilíngue, extralinguística, estratégica, instrumental, de conhecimentos sobre tradução e os componentes psicofisiológicos.

Da mesma forma, de acordo com as respostas fornecidas pelos Tradutores Públicos e Intérpretes Comerciais em atuação, identificamos que as habilidades e conhecimentos necessários para o bom desenvolvimento profissional identificam-se com o modelo de competência tradutória proposto pelo grupo PACTE (2005). Os profissionais citam como necessários conhecimentos linguísticos, culturais, específicos das áreas com as quais trabalha, habilidades de pesquisa, de leitura e componentes psicofisiológicos, como adaptabilidade, paciênciae disciplina.

Observamos que a diferença entre a literatura e a realidade atual está na forma em que o tradutor busca conquistar a competência tradutória. Enquanto a literatura esclarece que isso se dá pelo estudo formal, a trajetória dos tradutores demonstra a participação em cursos livres e o apoio na experiência adquirida com o passar dos anos. Acreditamos que a formação formal é essencial para o desenvolvimento das subcompetências que compõem a competência tradutória, pois abrange conhecimentos teóricos acerca da tradução e prática, fornecendo aos alunos a experiência necessária para capacitá-los ao mercado de trabalho.

Sendo assim, recomendamos que o perfil do Tradutor Público e Intérprete Comercial comtemple o estudo formal da tradução, fornecido por instituições de ensino superior. Recomendamos, também, a otimização das subcompetências tradutórias propostas pelo grupo PACTE (2005), a qual capacita o tradutor a desenvolver as habilidades e conhecimentos necessários para um bom desempenho profissional. 


\section{Referências bibliográficas}

ALBIR, A. H. A Aquisição da competência tradutória: aspectos teóricos e didáticos. In: Pagano, A.; MAgalhães, C.; Alves, F. Competência e tradução. Cognição e discurso. Belo Horizonte: Editora UFMG, 2005: 15-57.

ALVES, F. Um modelo didático do processo tradutório: a integração de estratégias de tradução. In: Alves, F.; MAGALhÃES, C.; PAGANO, A. Traduzir com autonomia. Estratégias para o tradutor em formação. Belo Horizonte: Editora UFMG, 2013: 113-128.

AUBERT, F. H. A tradução literal: impossibilidade, inadequação ou meta?.Revista Ilha do Desterro, n. 17, Florianópolis (UFSC),1987, pp. 17-20.

AUBERT, F. H. Tipologia da tradução: o caso da tradução juramentada. In: Encontro Nacional de Tradutores, n. 5, Salvador. Anais... São Paulo: Humanitas, 1996.

AUBERT, F. H. Tipologia e procedimentos da tradução juramentada. ICITRAT/FFLHC/USP, vol. 1-2, São Paulo, 1998.

AUBERT, F. H.; TAGNIN, S. E. O. Um corpus de traduções juramentadas: material de pesquisa linguística, sociológica e histórica. Tradterm, v. 10, São Paulo, 2004, pp. 163-178.

AUBERT, F. H. Dilemas da literalidade na tradução juramentada. Trabalhos em Linguística Aplicada, n. 2, Campinas, 2005, pp. 247-263.

BrasIL. Presidência da República. Casa Civil. Subchefia para Assuntos Jurídicos. Decreto-lei $n^{\circ}$ 13.609, de 21 de outubro de 1943. Estabelece novo Regulamento para o ofício de Tradutor Público e Intérprete Comercial no territórioda República. Rio de Janeiro, RJ, 1943.

Disponível

em:

<http://www.institucional.jucesp.sp.gov.br/downloads/DF13609 _43.pdf>. Acesso em: 19 nov. 2017. Publicado na CLBR em: 1943.

BRASIL. Governo do Estado de São Paulo. Secretaria de Desenvolvimento Econômico, Ciência e Tecnologia. Junta Comercial do Estado de São Paulo. Deliberação JUCESP $n^{\circ}$ 4, de 01 de novembro de 2000. São Pulo, SP, 2000. Disponível em: <http://www.institucional.jucesp.sp.gov.br/downloads/Delibera cao_Jucesp_04_de_01.11.pdf >. Acesso em: 19 nov. 2017. Publicada no Diário Oficial do Estado - Caderno da Junta Comercial em: 7 nov. 2000.

BRASIL. Presidência da República. Secretaria da Micro e Pequena Empresa. Secretaria de Racionalização e Simplificação. Departamento de Registro Empresarial e Integração. Instrução Normativa DREI $n^{\circ} 17$, de 5 de dezembro de 2013. Dispõe sobre a matrícula e hipóteses de seu cancelamento de administradores de armazéns gerais e trapicheiros; a habilitação, nomeação e matrícula e seu cancelamento de Tradutor Público e Intérprete Comercial; e o processo de concessão de matrícula, seu cancelamento e a fiscalização da atividade de Leiloeiro 
Público Oficial e dá outras providências. Brasília, DF, 2013. Disponível em:

<http://www.institucional.jucesp.sp.gov.br/downloads/instrucaonormativa_17.pdf>. Acesso em: 19 nov. 2017. Publicado no Diário Oficial da União em: 6 dez. 2013.

GOEDERT, A. O. Tradução juramentada e as modalidades de tradução: o caso dos históricos escolares. 2015. 129f. Dissertação (Mestrado em Estudos da Tradução) - Faculdade de Filosofia, Letras e Ciências Humanas, Universidade de São Paulo, São Paulo, 2015.

NovAES, A. P. M.O Tradutor: Formação inicial e as exigências do mercado de trabalho. Trabalho de Conclusão de Curso.Bauru-SP, 2012.

PAGano, A. As crenças sobre a tradução e o tradutor: revisão e perspectivas para novos planos de ação. In: Alves, F.; MAGalHães, C.; PAGANO, A. Traduzir com autonomia. Estratégias para o tradutor em formação. Belo Horizonte: Editora UFMG, 2013: 9-28.

Pagano, A. As estratégias de busca de subsídios externos: fontes textuais e recursos computacionais. In: Alves, F.; MAGALHÃES, C.; PAGANO, A. Traduzir com autonomia. Estratégias para o tradutor em formação. Belo Horizonte: Editora UFMG, 2013: 39-56.

WYLER, L. Língua, poetas e bacharéis: Uma crônica da tradução no Brasil. $1^{\circ}$ ed. Rio de Janeiro: Rocco, 2003.

Recebido em: 06/04/2018

Aceito em: 17/12/2018

Publicado em dezembro de 2018 